\section{EMBRYRIDDLE \\ Aeronautical University}

SCHOLARLY COMMONS

\section{International Journal of Aviation,} Aeronautics, and Aerospace

\title{
Professional Pilot Commercial Off-the-Shelf (COTS) EFB Usage, Policies and Reliability
}

\author{
Tyler A. Babb
}

Middle Tennessee State University, tyler.babb@mtsu.edu

Follow this and additional works at: https://commons.erau.edu/ijaaa

Part of the Curriculum and Instruction Commons, Educational Assessment, Evaluation, and Research Commons, Navigation, Guidance, Control and Dynamics Commons, Systems Engineering and Multidisciplinary Design Optimization Commons, and the Vocational Education Commons

\section{Scholarly Commons Citation}

Babb, T. A. (2017). Professional Pilot Commercial Off-the-Shelf (COTS) EFB Usage, Policies and Reliability. International Journal of Aviation, Aeronautics, and Aerospace, 4(1). https://doi.org/10.15394/ ijaaa.2017.1159

This Article is brought to you for free and open access by the Journals at Scholarly Commons. It has been accepted for inclusion in International Journal of Aviation, Aeronautics, and Aerospace by an authorized administrator of Scholarly Commons. For more information, please contact commons@erau.edu. 


\section{Professional Pilot Commercial Off-the-Shelf (COTS) EFB Usage, Policies and}

Reliability

\section{Cover Page Footnote}

This project would not have been possible without the significant participation of active professional pilots across more than 80 different flight operations in the United States. The author is thankful for the participation. 
This study was conducted to determine how common EFBs use is among commercial flight operators in the United States, including the devices and software currently in use, operators' EFB policies, and conduct a preliminary investigation into EFB reliability. The term "operator" was used because not all flight operations are considered air carriers, such as Part 91 corporate flight departments. Secondary goals included determining the limitations of these devices and software as well as specific uses of the software.

Most commercial operators must comply with FAA requirements to implement EFB usage. This study discovered how operators comply with predetermined FAA policies and guidance. These discoveries provide operators and pilots with useful information including (1) common EFB hardware and software, (2) common policies found for other EFB operations, and (3) reliability information to become more informed on which operator that pilot may wish to fly for and/or which EFB device or software may be preferred by an operator. The EFB industry has also spread to pilot training. This information can inform flight schools on how to implement EFB policies and practices like those of commercial operators. Several papers have been published to document current EFB options for operators. However, direct input from the pilots that use them provides useful information.

\section{Literature Review}

An air carrier cannot simply buy tablets, install software, and then use EFBs. The Federal Aviation Administration provides guidance on EFB implementation and requirements for operational approval in Advisory Circular 120-76C. The approval process described within includes a six-month trial period including five phases. Air carriers must receive approval from their respective FAA authorities to use EFBs, specific to the class and type of EFB, including validation of EFB reliability (FAA, 2014). Also, the operator's principal inspector (PI) must authorize specific tasks as requested, including EFB access to documents as operations manuals, standard operating procedures, maintenance manuals, and minimum equipment lists (FAA, 2014). The advisory circular previously mentioned provides lists of examples of EFB functions requiring FAA principal inspector approval. However, FAA operational approval is not needed for Part 91 corporate flight departments.

Airlines such as Virgin America, U.S. Airways, and Piedmont were all implementing or using EFBs as of September of 2015 (Hughes, 2009). Southwest Airlines is one of the largest 121 operators in the United States and employs more 
than 9,000 pilots. Every Southwest pilot was using an Apple iPad EFB as of 2015 (Thompson, 2015).

However, American Airlines was the first major airline in the U.S. to begin implementing Apple iPad EFBs in 2013 (Van Wagenen, 2015). At that time, the company employed more than 8,000 pilots. Before obtaining operational approval, the airline was required to prove that EFB software revisions would not "corrupt the data integrity or intended function of the original installed software configuration" (FAA, 2014, p. 7). Ironically, it only took a few years before a major flight operation was affected by EFB problems. On April 27, 2015, an application problem grounded more than 20 American Airlines flights. A duplicate chart in the database caused the application to crash, leaving many pilots in the cockpit without charts (Van Wagenen, 2015). Ultimately the problem was solved by uninstalling and reinstalling the software on the tablets, but not before delaying or even canceling multiple flights. This occurrence bred a resounding consideration by other operators to carry paper backup charts in the cockpits in addition to the two EFBs, though not required by the FAA after initial EFB approval if two approved EFBs are on board (FAA, 2014, p. 10).

There are several factors that must be considered when using an EFB, such as chart currency and battery charge for dispatch. Electronic charts themselves are easy to update in comparison to their former paper counterparts. With one touch an entire chart database can be queued to download and typically will update within several minutes. Battery life was also a primary concern, and AC 120-76C states that useful battery life must provide for "taxi and flight operations to include diversions and expected delays" (FAA, 2014, p.11). Operators are required to implement policies and training on EFBs, including rules about minimum battery charge for dispatch. Southwest Airlines has a minimum EFB battery charge for each flight based on flight length (Thompson, 2015). Other operators may base the minimum charge on pilot duty time or number of legs.

Internet connectivity can be critical when pilots need access to information on the EFB. If the charts required are downloaded onto the hard drive, then the pilot will be able to access the data in flight without an internet connection. However, depending upon the hardware and software combination, some charts may require an internet connection and will not be available when the device has no internet connectivity. This could be a major problem if unnoticed prior to departure. Several major airlines currently offer internet connectivity on board flights to both pilots and passengers. Onboard network systems, when designed carefully, should exclude the flight crew information systems from the common passenger networks 
and entertainment services (Sampigethaya, Poovendran, Shetty, Davis, \& Royalty, 2011).

The FAA allows pilots to access navigation charts on the EFB. In addition, the FAA also grants additional EFB functions including preflight and in-flight weather data. However, EFB weather information during flight cannot be used as the primary source of weather information for making in- flight decisions regarding flight safety (FAA, 2014, p. 8). EFB Data Link weather capabilities such as NEXRAD may help pilots tremendously in a bad weather, but must be supported by other weather information systems.

Electronic navigation charts have proved to be reasonably reliable and easy to use, but tablet EFBs are capable of much more than just displaying charts on a screen. During the flight, if connected to the internet, pilots can view real-time weather, calculate performance, view NOTAMs, track maintenance, and perform many other flight-related job functions (FAA, 2014). Unfortunately, COTS tablets, though used for chart applications, remain limited in their ability to replace previously established electronic checklists (ECLs). The COTS tablet, when used as a Class 1 or $2 \mathrm{EFB}$, is not and cannot be integrated into the aircraft systems, such as previously approved ECL systems (Myers, 2016).

The Volpe Center is a division of the U.S. Department of Transportation and is widely involved in human factors research related to EFBs. In 2003, Divya Chandra and Michelle Yeh updated a document titled Human Factors Considerations in the Design and Evaluation of Electronic Flight Bags. In addition to detailed guidance on the assessment of these devices, the researchers discovered that the International Civil Aviation Organization (ICAO) sets standards for chart format, and many nation states publish charts in accordance with these standards. However, EFB software providers such as Jeppesen are not required to follow ICAO standards for chart format (Chandra \& Yeh, 2015). This could create issues of standardization if a pilot were to transition from one software platform to another. Advisory Circular $120.76 \mathrm{C}$ reinforces the human factors approach EFB implementation, with references to the clarity of text displayed based upon reasonable viewing distances as well as the responsiveness of the device and software (FAA, 2014, pp 16-19).

EFBs may also have adverse effects upon flight safety. An independent study of NASA ASRS and NTSB reports related to EFBs was performed by Dr. Divya Chandra and Andrew Kendra in 2010. In their study, they identified 37 relevant reports from private and commercial pilots, and air carriers accounted for 
$24 \%$ of the reports. The research discovered that the most common pilot errors associated with EFB usage were deviation from assigned headings, altitudes or airspeeds (Chandra \& Kendra, 2010). The research also indicated that 28 of the reports were linked to chart software. The most common troubles that pilots had when accessing information related to the display configuration (14), being new to the EFB (10), and miscellaneous EFB operation issues (7) (Chandra \& Kendra, 2010). Familiarity with EFB systems is required for operators, as they must establish a training program and evaluate that program for approval. As for the pilots in these reports stating unfamiliarity with EFBs, they may or may not have been commercial pilots trained on EFBs by an operator. Several of these issues are warned about in Advisory Circular 120.76C, and the FAA states that human factors/pilot interface with the EFB system must also be evaluated, including issues such as text legibility, responsiveness and other active manipulation (FAA, 2014).

There are many options for tablet EFB devices and software. An industry survey of available EFB products was conducted by the John A. Volpe National Transportation Systems Center in 2015 as a follow-up to a similar study in 2010. The 2015 industry survey categorized the products according to what the company produced (i.e. hardware only, hardware and software, or software only). At the time of the survey, researchers received responses from more than 46 software manufacturers and 19 hardware manufacturers. The software companies that provide EFB software on tablet computers have integrated pilots who are active in the industry for the development and evaluation of their software. For example, Jeppesen receives feedback from a pool of 58 active commercial pilots from all backgrounds (Lau, 2016). Also, apart from Apple and Microsoft tablets, this study identified several other tablet manufacturers including SAT-WAY, Scandinavian Avionics Group, Avmap, CMC electronics, and DAC International (Hiltunen, Chase, Kendra, and Jo, 2015).

The sports and entertainment industries have also adopted tablet computers. During a recent NFL football game, Bill Belicheck, the head coach of the New England Patriots, became so frustrated with a Surface tablet he threw it on the sideline. He was later asked about the incident and said that the tablets were not yet reliable enough, so he would continue to use paper instead (Mather, 2016). The environment in which the EFB is used should always be considered, as NFL coaches require timely access to data, which is somewhat similar to the environment in which pilots work.

How do operators put such information into practice? Operators must choose an EFB device and software. More importantly, they must comply with all 
FAA guidance and implementation requirements. The FAA provides many EFB requirements in AC 120.76C, but an operator may choose a unique approach for compliance. This study discovered these policies and procedures and determined EFB reliability.

\section{Methodology}

This research used the FAA guidance on EFB operational approval (AC 120.76C) to develop survey questions for active commercial pilots. The first four questions gathered general data about the pilots' types of operation and personal opinions on EFB use during primary flight training. The survey then gathered historical data to track the growing EFB usage among operators dating back to 2013. Additional survey questions were based upon the requirements of AC 120.76C. Individual survey questions and references to AC 120.76C are listed in Appendix A.

Data for this study was gathered via an online survey using surveymonkey.com. The study was advertised on the Facebook web page for the Aerospace Department of Middle Tennessee State University. The Facebook page had more than 1,200 followers that could have potentially seen the advertisement, but not all followers were qualified to take part in the survey, as not all followers were active professional pilots. The survey was also distributed in the Curt Lewis Aviation News email feed, which has 36,000 subscribers worldwide. Again, not all subscribers were qualified to participate. Data was gathered from January 16 to January 28, 2016. The MTSU IRB protocol number for data collection was 161099.

As for sampling, the goal was to gather data from all facets of commercial flying, including major airline pilots, regional airline pilots, and corporate airline pilots at Part 91 flight departments in the United States. As of May 29, 2015, there were 114 certificated air carriers based in the United States (DOT, 2015). However, several professional pilots may fly for Part 91 operators which do not hold an air carrier certificate.

The survey included quantitative and qualitative data and included multiple choice, Likert-type, and open-ended questions. The participants' employer/operator names were gathered to ensure an industry-wide dataset. However, operator names were not linked to any other data provided by the participants and will not be reported in this manuscript. 


\section{Participants}

There were 236 active professional pilots that participated in the survey. Most participants worked for American-based operators, while very few participants (4) flew for foreign carriers that had destinations within the United States. The sample represented 40 of the 114 U.S. air carriers (35\%). As expected, the Part 91 professional pilots represented a large variance in operators, accounting for 35 survey responses representing 27 different operators. The data collected was a representative sample of commercial pilot operations within the United States. Professional flight instructors were not included, and one response was removed for this reason.

\section{Results}

The results indicated that EFB usage is widespread throughout the industry, with small variations in the types of devices and software used. Most participants indicated that their company had been using EFBs for more than one year as of January, 2016. Though several hardware and software combination are commercially available, there were products that were overwhelmingly used. Operator EFB policies and procedures were mostly similar but had some minor variations. The participants generally agreed that it would be beneficial for student pilots to use EFBs during initial flight training. In addition, some software/hardware combinations proved to be more reliable than others.

The first question on the survey identified the type of operation for each participant. The responses available included (1) Part 121 Major Airline, (2) Part 121 Regional Airline, (3) Part 121 Air Cargo, (4) Part 135 Air Charter, (5) Part 91, and (6) Other. The participants that responded "Other" included Part 121 Charter, U.S. Federal Government, Air Ambulance, U.S. military, and Law Enforcement. Most participants (72\%) were Part 121 airline pilots. The second most common type of operation was Part 91 (15\%). Some participants which replied "other" mentioned that they flew both Part 135 and Part 91 flights. The results of this question are displayed in Figure 1.

There were five operators that had 10 or more participants, with the most represented operator having 32 participants. This information could have impacted the results, as those 32 participants should have answered several questions similarly based upon company EFB policies and procedures. This group of pilots represented less than $14 \%$ of the total responses. The number of represented operators by type of operation are displayed in Table 1 . 


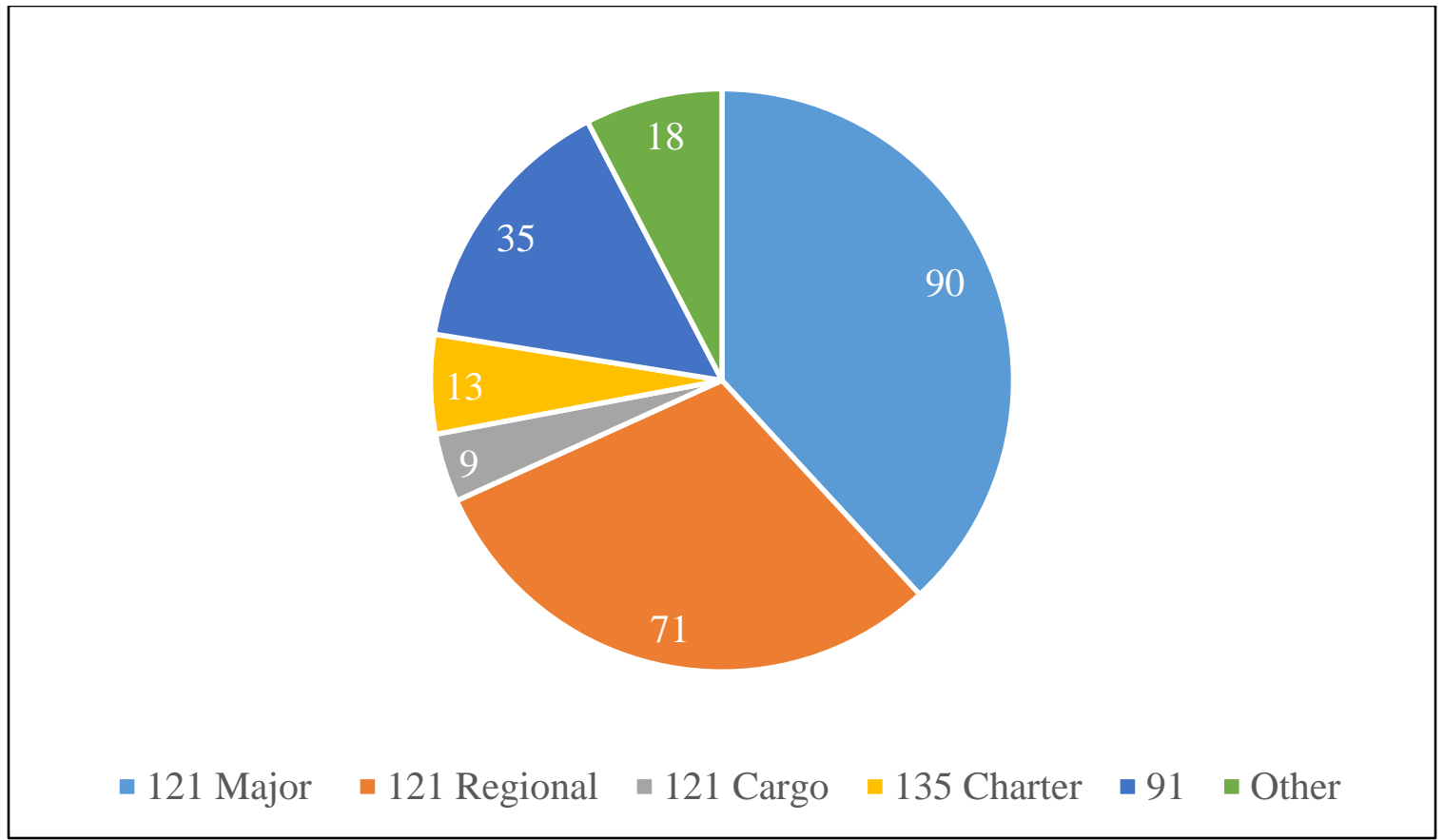

Figure 1. Number of Participants Indicating Employment with Each Type of Operation

Table 1

Number of Operators Represented by Participants

\begin{tabular}{|l|c|}
\hline 121 Major Airline & 15 \\
\hline 121 Regional Airline & 14 \\
\hline 121 Air Cargo & 7 \\
\hline 135 Charter & 8 \\
\hline Part 91 & 27 \\
\hline Other & 10 \\
\hline
\end{tabular}

The COTS EFB industry is a still in its infancy, and the next survey question identified proposed changes in company policy as it related to EFB usage. Participants were asked to identify any of the following actions that his/her company had planned to take: (1) switch from paper charts to EFBs, (2) change or update the EFB device in use, (3) change or update the EFB software in use, and (4) none of the above. More than half of the participants (63\%) indicated that their 
operation plans to make changes to their EFB policy, while $37 \%$ of participants indicated no plans to change EFB policy. Figure 2 displays this data.

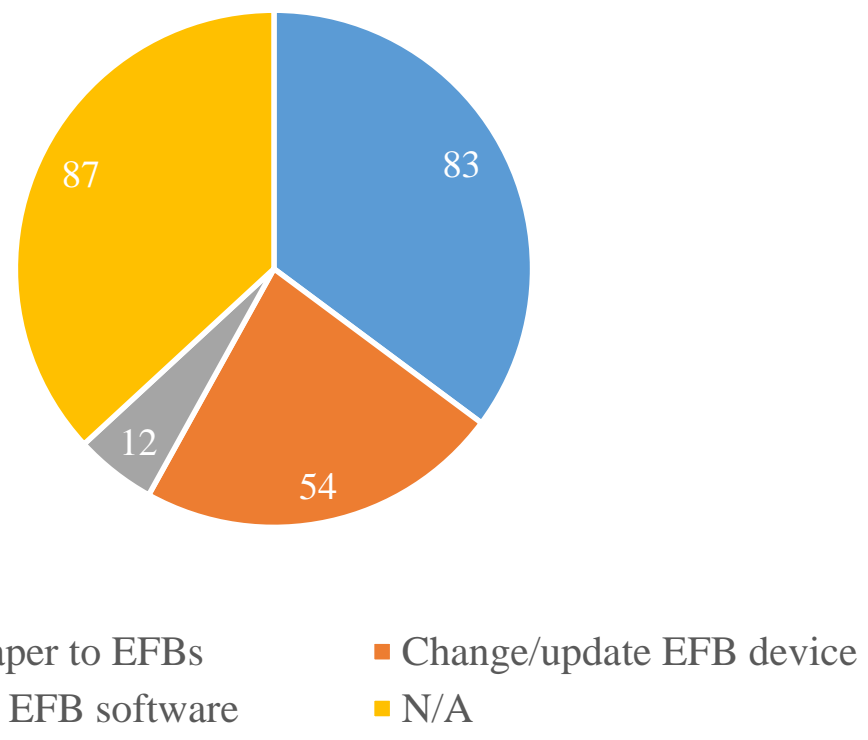

Figure 2. Number of Participants Indicated Planned Changes to Operator EFB Policies and/or Usage

The subsequent question gathered qualitative data. Each participant was asked a Likert-type question responding to the statement "I believe that current professional pilot students would benefit from using electronic flight bags during their initial training." The majority of participants either agreed or strongly agreed with the statement, as shown in Figure 3. Using a Chi-square test, the data indicated that responses were statistically significant $\chi^{2}(4, n=236)=119.381, p<0.0001$. 


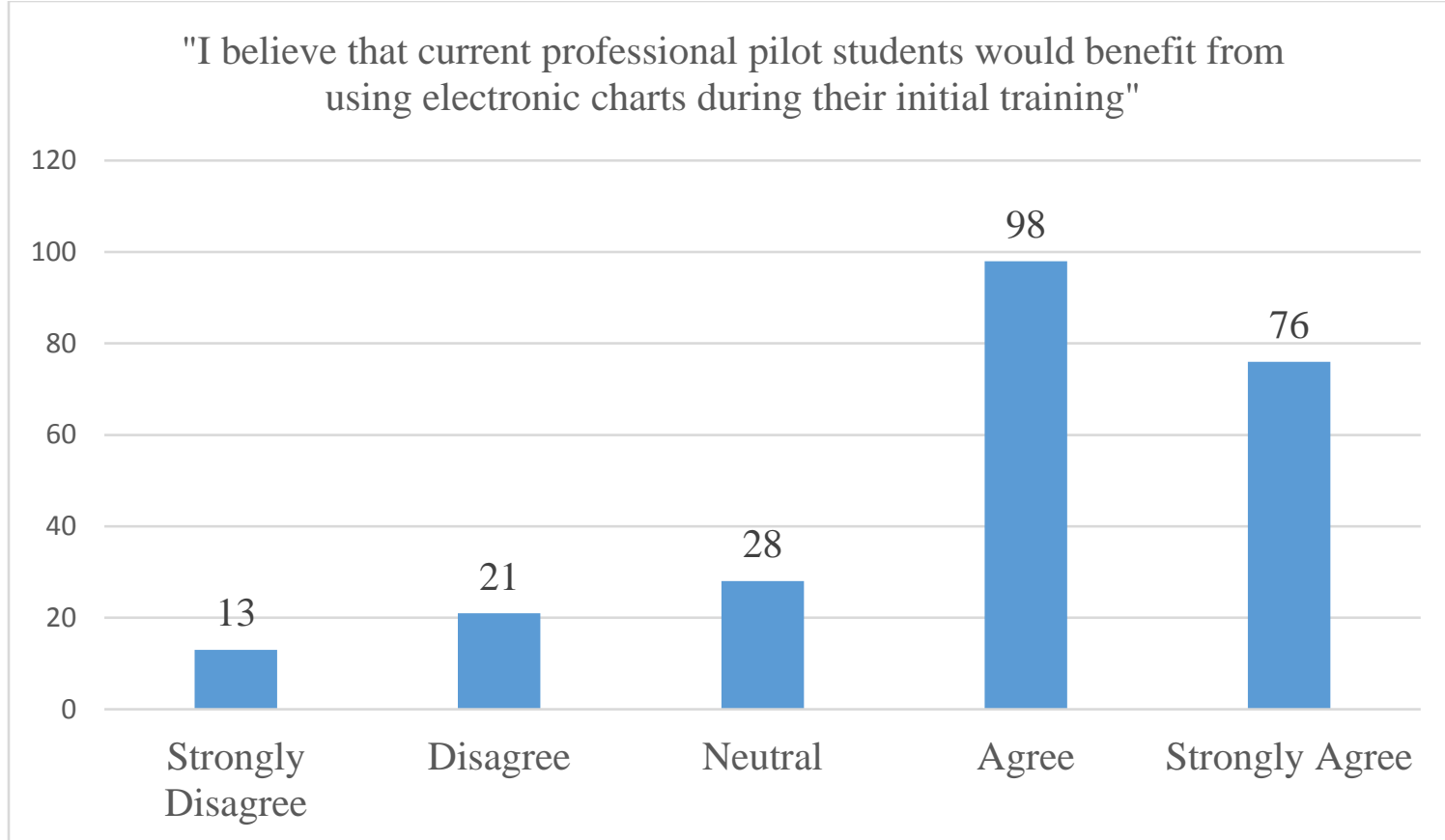

Figure 3. Participant Opinions on Initial Flight Training with EFBs

Not all participants were currently using EFBs when they completed the survey. It could be possible that current commercial pilots have used EFBs before, but do not currently use EFBs for their current flying job. The next survey question asked, "If your company does not currently use EFBs, have you ever used one before in flight training or at another company?" This question was not applicable for the majority of participants, but 35 participants $(15 \%)$ had at one point used EFBs and were not currently using them. Only eight persons (3\%) had never used EFBs.

The next survey question confirmed the prevalence of EFB usage in the professional pilot industry. Participants were asked, "Does your company currently use EFBs in any manner (including trial period)?” Only seventeen participants indicated their operator did not use EFBs in any form. These results are displayed in Figure 4.

After identifying which participants currently used EFBs, the next survey question identified how long EFBs had been in use for particular operators. Participants were asked "How long has your company been using EFBs?" The majority of participants (72\%) indicated that their company had been using EFBs 
for at least one year as of 2016. This data is summarized in Figure 5. There were 219 participants whose operator was currently using EFBs at the time of the survey, but 13 did not continue the survey to answer specific questions about their EFBs. This might indicate that some companies were still in a trial period, and not all pilots were using EFBs, or that certain participants decided to stop taking the survey at that point.

Does your company currently use EFBs in any manner (including trial period)?

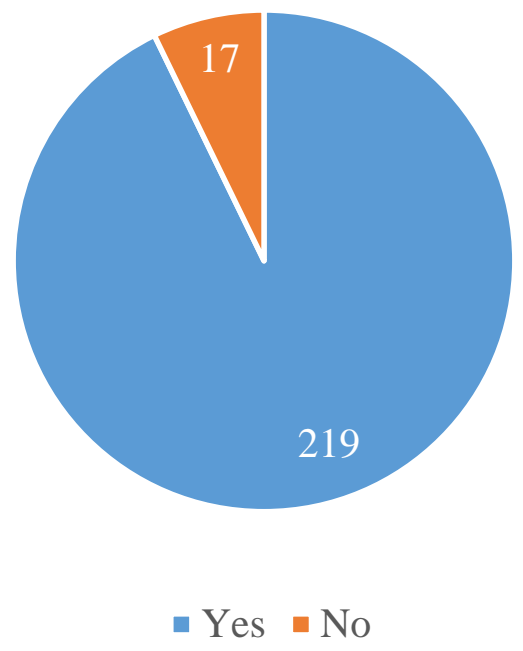

Figure 4. Number of Participant Indicating EFB Usage at Their Current Flight Operation

At the time of the survey, there were 219 participants currently flying with COTS EFBs, and 206 of those participants continued the survey. The types of devices used were identified by the next survey question. Participants were provided with the following options: (1) Microsoft Surface, (2) Apple iPad, (3) Android, and (4) Other. The Apple iPad was the dominant device, accounting for $85 \%$ of the COTS EFBs in use. The Microsoft Surface series tablet was the second most reported, representing $11 \%$ of participants. Participants that selected "Other" included the Toughbook, EMI, Boeing EFB, and other permanently installed EFBs (non-COTS). This data is summarized in Figure 6. 
The subsequent survey question identified the software used by participants. Jeppesen software was the most common software, accounting for $78 \%$ of the responses. Other software available on the survey question were ForeFlight Mobile, Garmin Pilot, WingX, and Other. Responses for "Other" included Lido (4), Avare (1), Navtech (6), Lufthansa mPilot (2), Aero (1), NGA (1), and E pubs (1). Six participants indicated that they use both Jeppesen and Foreflight software and were then accounted for in both categories. The responses are summarized in Figure 7.

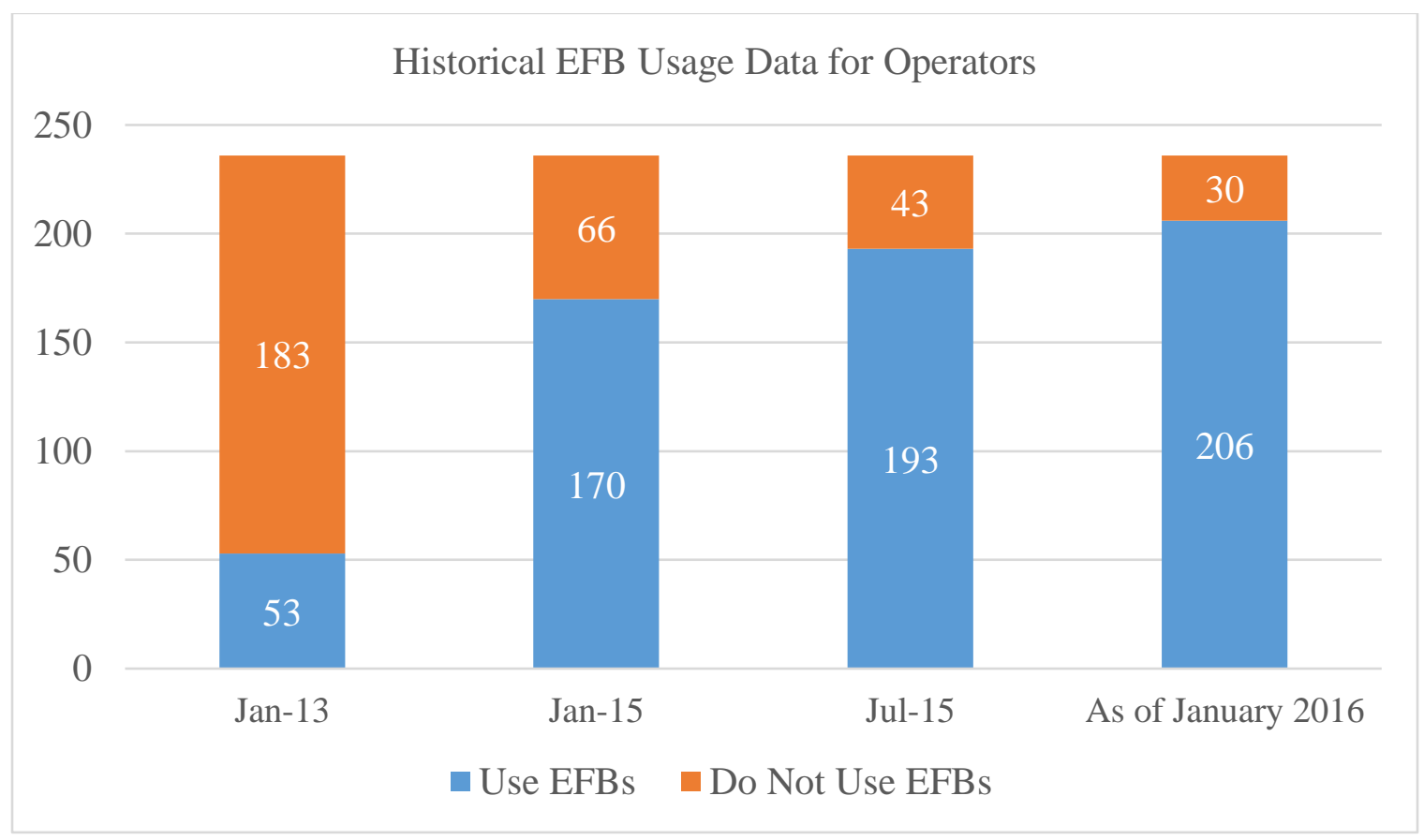

Figure 5. Number of Participants Which Indicated Duration of EFB Use by Operator

Operators may be capable of charging the EFB device in flight. This could nullify minimum battery charge for dispatch, and add to pilot confidence in the EFB during flight. Charging capabilities for participants were identified with the next survey question: "Are you able to charge your device in flight on any aircraft you are currently assigned to? This may or may not include all aircraft or tail numbers of one type." The qualifying statement was necessary, as not all aircraft types for a particular operator's fleet may have the necessary hardware on board to charge devices. The responses were split, with $66 \%$ indicating they could charge the device in flight, and 34\% indicating they could not. 
International Journal of Aviation, Aeronautics, and Aerospace, Vol. 4 [2017], Iss. 1, Art. 8

Which type of device does your company use as an EFB?

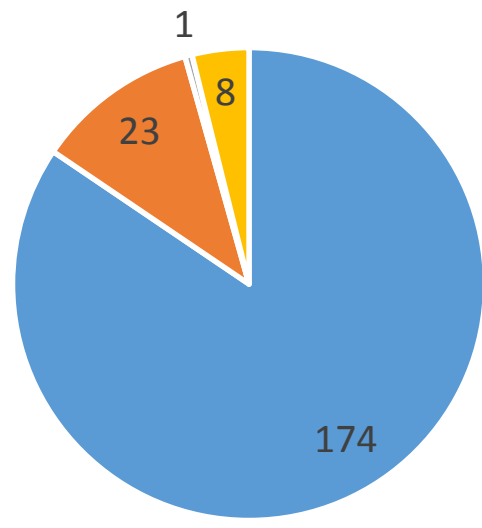

- Apple iPad $\square$ Microsoft Surface $\square$ Droid $\square$ Other

Figure 6. Number of Participants Indicating COTS EFB Tablets Used by Operators

What chart software or app does your company currently use?

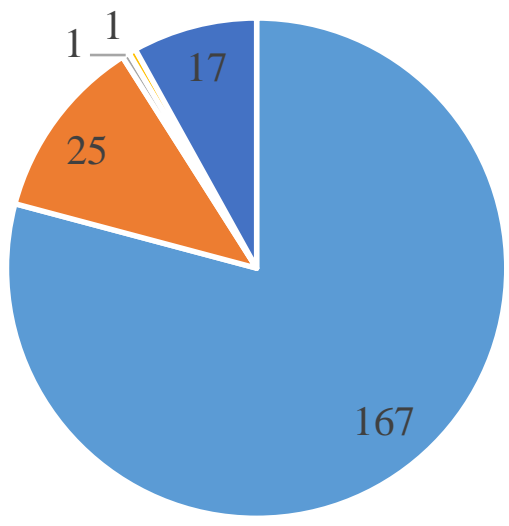

- Jeppesen $\quad$ ForeFlight $\quad$ Garmin Pilot $\quad$ WingX $\quad$ Other

Figure 7. EFB Software Usage as Identified by Participants 
Each air carrier has specific requirements for EFB battery charge before dispatch as required for operational approval by AC 120.70C. The next survey question asked, "Is there a minimum battery charge needed for departure on the pilot(s) EFB(s) according to your operations specifications and EFB authorization?" Surprisingly, 44 pilots (21\% of responses) indicated that they did not have a minimum battery charge required for departure. This could have been because Part 91 professional pilots can use EFBs without operational approval, and there were 35 applicable participants, and of the 30 which answered the question, 16 indicated no minimum charge for dispatch. However, 162 of the 206 total applicable participants $(79 \%)$ stated that there was a minimum charge for departure.

If participants indicated a minimum battery charge for departure, they were then asked what specific charge was required. These open-ended responses were categorized as requiring charge based upon (1) minimum to start a duty time, (2) planned flight hours or duty time, or (3) the number of legs scheduled for the day. The majority of applicable responses (142 of 162) provided enough detail to be categorized into one of these three categories, but some responses (15 of 162) did not give sufficient detail or skipped the question. Three participants indicated they did not know the required charge.

The majority of applicable participants (117 of 162) indicated that if a battery charge is required, the amount of charge is based upon the charge at the start of the duty day. The average charge requirement at the start of the day was $80 \%$, with some participants indicating requirements as high as $100 \%$ and as low as $10 \%$. Other operators (19) required a certain battery charge based upon the planned flight hours or duty time. Common responses indicated either $10 \%$ per hour of duty or number of flight hours plus $10 \%$. Only six participants that indicated a minimum charge requirement for departure responded that the charge was based upon the number of legs planned for the day.

Participants were then asked if their company required paper backup charts in case they had an issue with accessing information with the EFB. The majority of participants $(70 \%)$ indicated that there was no requirement to have paper backup charts on board, and only $30 \%$ of the participants stated that their operator requires them.

In addition to navigation charts, the EFBs are used to access many other types of flight-related information. Participants were asked to indicate the FAA approved functions of their EFBs including the data listed in Figure 8. The most common responses included navigation charts, minimum equipment lists, and 
preflight weather information. Participants that responded "other" had the approval to use the EFB for airplane flight manuals, flight operations manuals, deicing data, checklists, company handbooks, EFB manuals, quick reference handbooks, training/recurrent training, and standard operating procedures.

The final survey question asked "Have you ever had trouble accessing information on your EFB during preflight or in-flight? If you answer yes, please explain." Approximately one in three applicable participants (69 of 206) reported some problem with their EFB during preflight or in-flight. At the time the survey was conducted, many of the associated operators had been using EFBs for one to three years.

After establishing the rate of EFB problems among the participants, the survey then asked for details related to the complications. Of the 69 participants that reported problems accessing EFB information, 66 provided explanations of the issue. This was an open-ended question, but most responses fell into the following categories: (1) a crash or freeze of the software or hardware, (2) updates causing problems, (3) the user interface, or (4) a lack of internet connectivity. Some participants reported more than one type of issue. Figure 9 shows a summary of these responses.

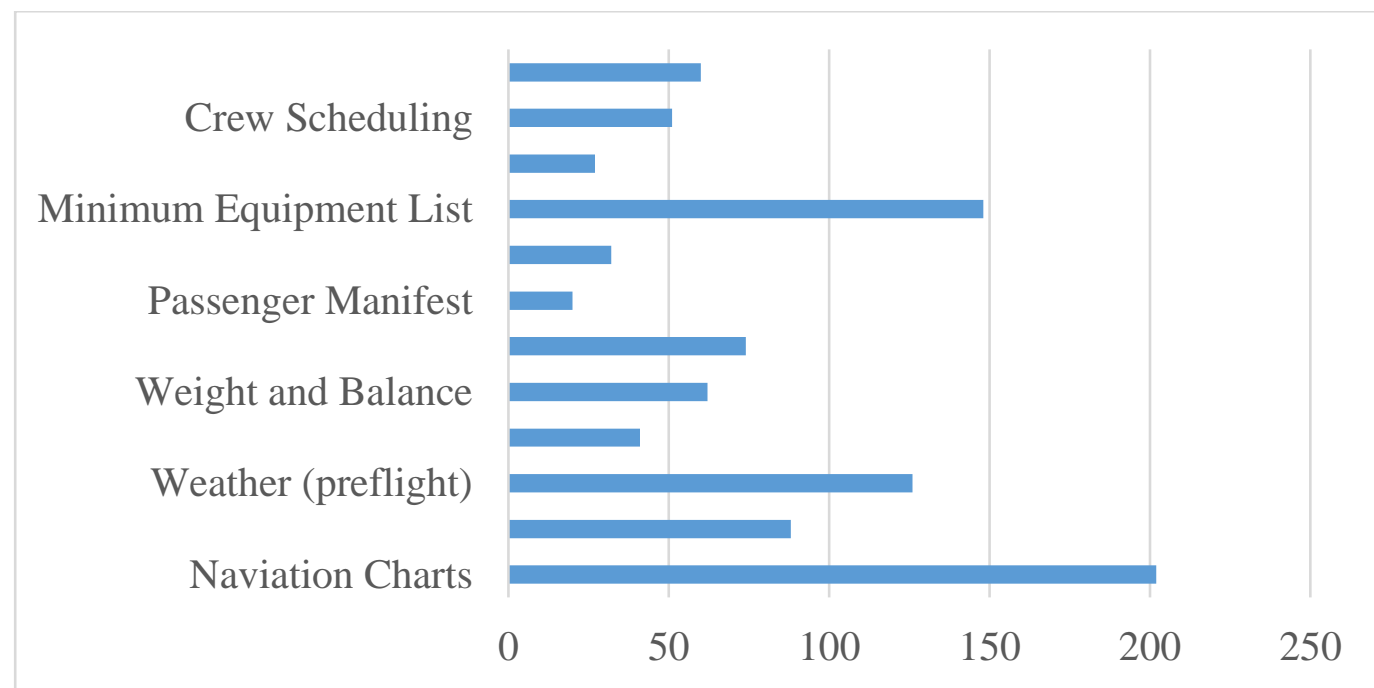

Figure 8. Number of Participants Indicating Particular EFB Functions as Approved by the FAA 


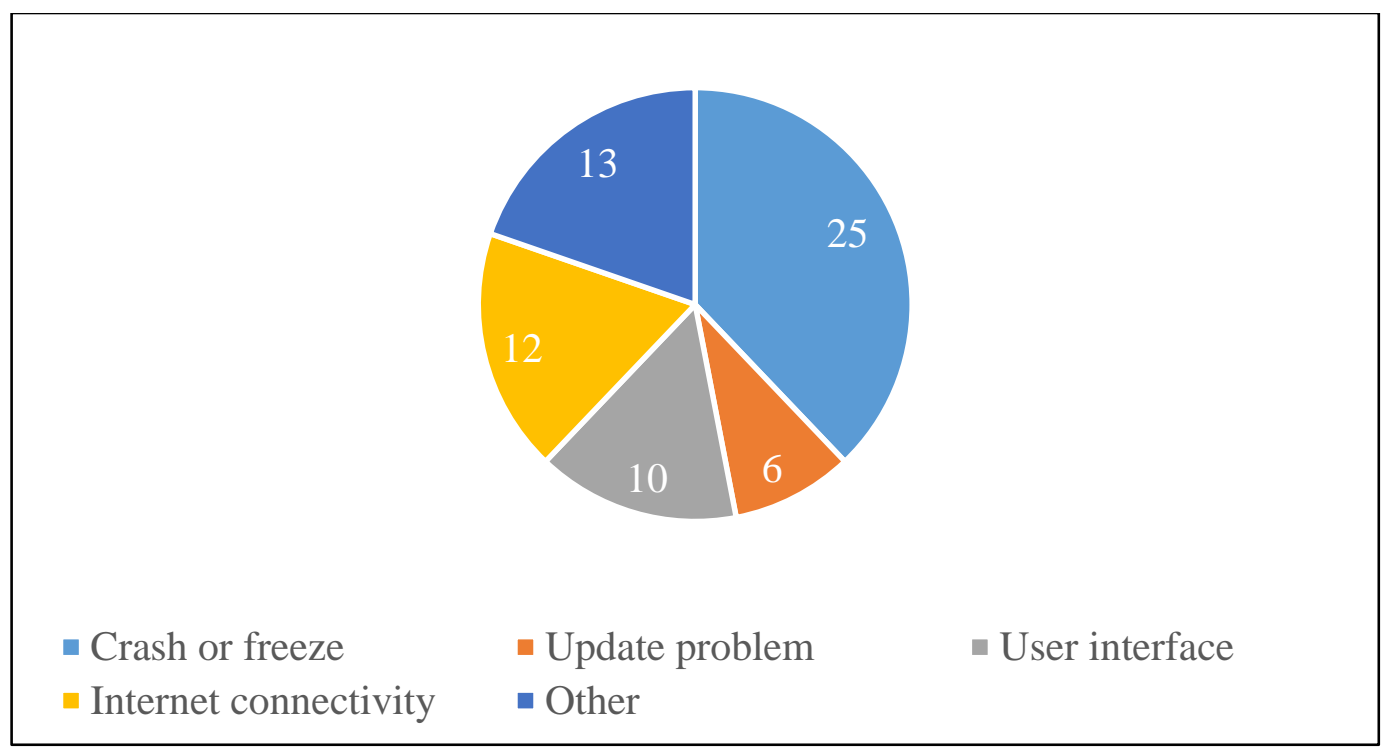

Figure 9. Number of Participants Reporting Trouble Accessing Information on EFBs During Preflight or in Flight by Category

A software crash or freeze was the most commonly reported issue (25 responses). In most cases the participants were unaware as to whether the crash/freeze issue was caused by the software or the hardware. In the case of application crashes or screen freezes, one participant stated that it happened once per day. Updates to the software were suspected to cause crashes of the application, as six participants believed that the update itself is what led to a crash. In one case, a participant reported that after an update, the "favorites" files within the application needed to be reorganized. In another case, the pilot started an operating system software update just prior to flight, and then canceled the update to go fly. Because the update never finished, the pilot did not have the ability to use the application during flight. In another case, all three on board EFBs were rendered unusable due to a software update. Unfortunately, all three EFBs used the same software, so a software complication disabled three separate devices on one airplane.

Twelve responses indicated trouble accessing information with the EFB due to internet connectivity. These responses included issues such as (1) the need to return to the gate to get WiFi prior to departure, (2) lack of consistent WiFi, and (3) inability to get weather information without WiFi. Each participant reported on his or her personal work environment, which may include variations in connectivity on 
the ground and in the air. Even though some aircraft were reported to have WiFi on board, one participant stated that it must be deactivated below 10,000 feet on departure or approach. If the internet connection is lost, it was reported that software could crash or fail to open. This is particularly troubling because at these are critical phases of flight.

Additional problems included user interface issues (10 reported problems). The most commonly reported interface problem is finding information. The pilots knew what information they needed, but were unable to navigate the software to find it. Other user interface problems included complaints about the software being "cumbersome" or slow to respond, problems zooming in or out, missing data at different zoom scales and letters/information font size.

The participants that fell into the "other" category for EFB problems included a plethora of specific issues. Overheating, screen rotation, screen brightness, user inexperience, hardware storage issues, and inability to open the application were all reported. Despite the variance in these issues, the attempts made by the participants to fix the issue was quite standard: turn it off and turn it back on (7 participants).

The data was then further analyzed to determine if the type of software or type of device had any relationship with the reliability of the EFB. The most common devices were the Apple iPad and the Microsoft Surface tablets. In addition, the most common software/applications used were Jeppesen and ForeFlight. In consideration of this information, these software and devices were isolated to determine any reliability differences.

First, the software applications were analyzed for "trouble accessing information" regardless of the respective hardware (tablet) in use. Jeppesen was the most common software used (161 participants), and ForeFlight Mobile was the second most common software used (20 participants). Because each associated participant indicated the duration of EFB usage for their operator, analysis of the data then indicated the chances a pilot could have trouble accessing information on the EFB depending upon duration of use and survey responses. The data indicated that if a pilot used either software for more than three years, there was a significant chance you will have trouble accessing information on that software. For Jeppesen software, the chances were $32 \%$ after three or more years of use, and for ForeFlight Mobile, that chance was $28 \%$. This data is reflected in Figure 10. 


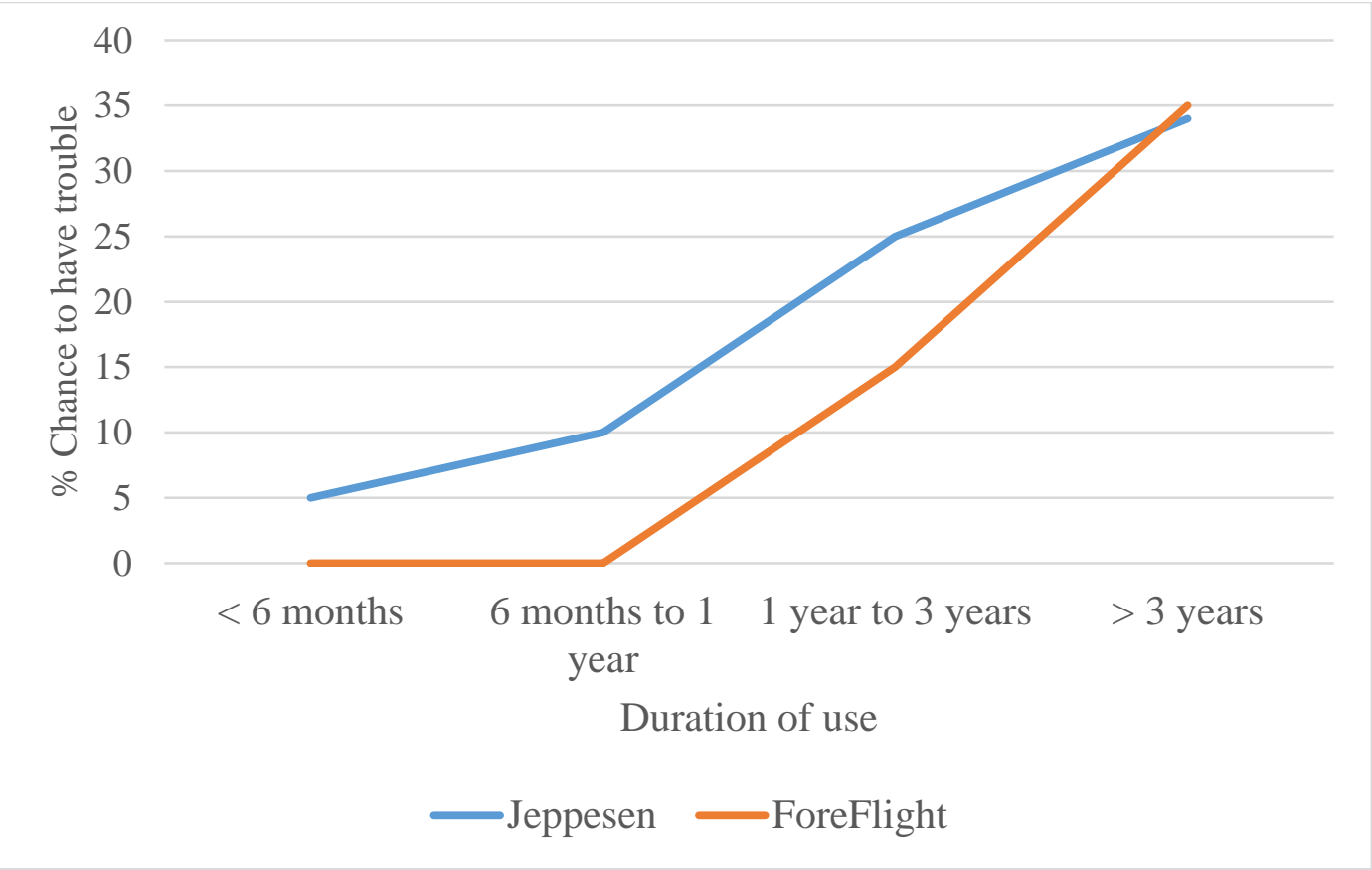

Figure 10. Chances of Trouble with Jeppesen and ForeFlight Software (regardless of hardware) Based Upon Survey Responses.

More data was analyzed per type of device used. The Jeppesen application was the most common software used, but this software was used on different devices, notably the Apple iPad and the Microsoft Surface. Additional analysis discovered a significant disparity between the reliability of the COTS tablets. The question "have you ever had trouble accessing information on your EFB?" was further investigated. Responses to this question for Jeppesen software users on the iPad and Surface were then separated by the COTS tablet. These individual responses were then traced to the duration of use for that specific participant's company. Based on participant responses, the Jeppesen software, when used on an Apple iPad, indicated a "trouble rate" of 27\% (36 of 133 participants) through more than three years of use. The same software, when used on a Microsoft Surface tablet, indicated a "trouble rate" of 68\% (15 of 22 participants) for up to three years of use. These trouble rates are indicated in Table 2 and Figure 11. At the time of the survey, none of the participants had been using Jeppesen software on a Microsoft Surface tablet for more than three years. 
Table 2

Aggregate Number of Participants Reporting Trouble with Jeppesen Software on Microsoft Surface and Apple iPad

\begin{tabular}{|l|c|c|c|c|}
\hline Duration of use & $\begin{array}{c}\mathbf{6} 6 \\
\text { months }\end{array}$ & $\begin{array}{c}\mathbf{6} \text { months }-\mathbf{1} \\
\mathbf{y r}\end{array}$ & $\begin{array}{c}\text { year }-\mathbf{3} \\
\mathbf{y r s}\end{array}$ & $\begin{array}{c}>\mathbf{3} \\
\text { years }\end{array}$ \\
\hline SFC (22 users) & 8 & 11 & 15 & NA \\
\hline \% trouble & $36 \%$ & $50 \%$ & $68 \%$ & NA \\
\hline iPad (133 users) & 0 & 4 & & 36 \\
\hline \% trouble & $0 \%$ & $3 \%$ & $19 \%$ & $27 \%$ \\
\hline
\end{tabular}

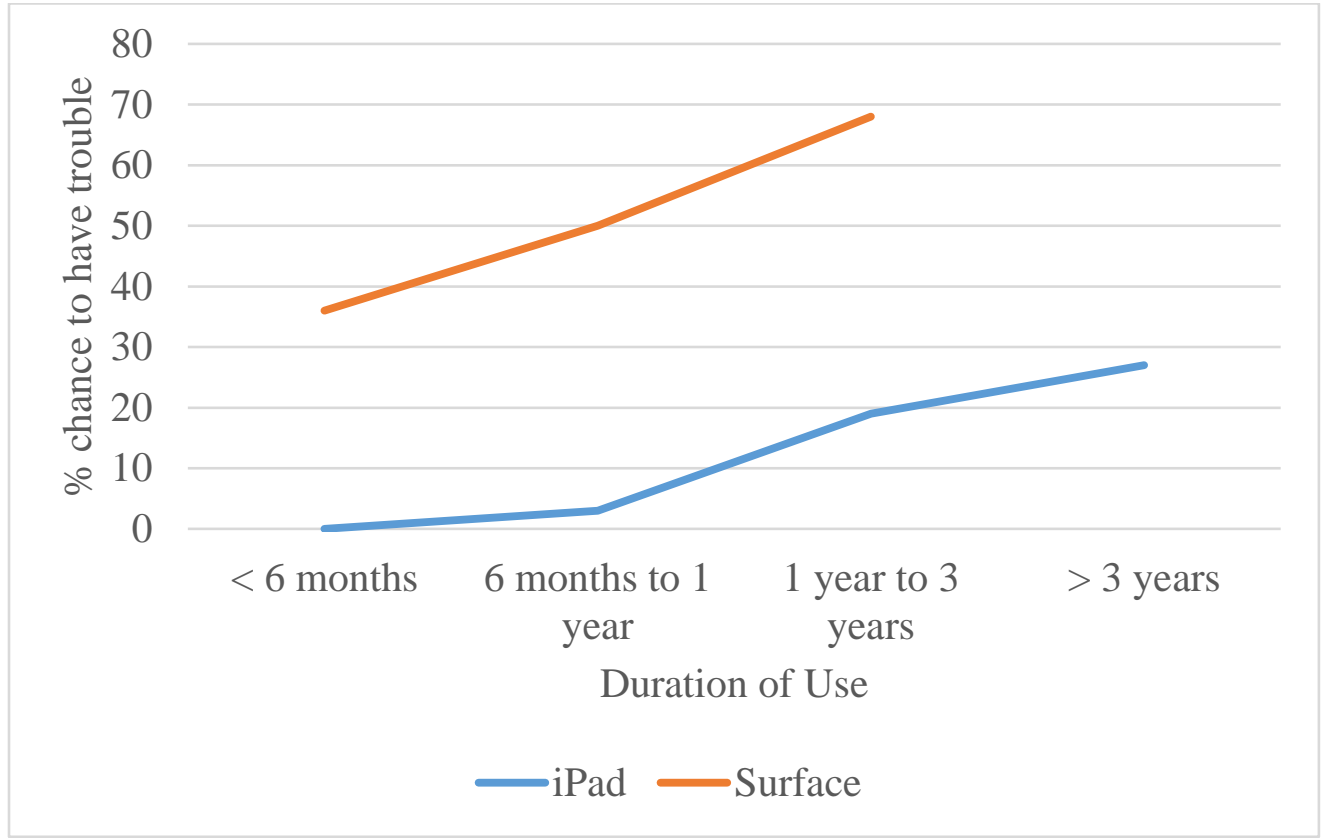

Figure 11. Chance to Experience Trouble with Jeppesen Software on iPad and Surface COTS Tablets Based Upon Survey Responses. 
To investigate the statistical significance of this disparity, a one-tailed Chisquare test for independence was used. The null hypothesis $\left(\mathrm{H}_{0}\right)$ stated that Jeppesen had similar trouble rates when used on an iPad and a Surface tablet. Based on the test, the data rejected the null hypothesis $\chi^{2}(1, \mathrm{n}=155)=24.05, p<0.005$. There is a clear relationship between the COTS hardware used and overall EFB reliability when using Jeppesen software. Jeppesen software is significantly more reliable when used on an iPad tablet versus when used on a Surface tablet.

\section{Discussion}

As expected, the clear majority of operators were using EFBs at the time of the survey and had been using them for at least one year. It was noted that of 236 participants, only eight (3\%) had never once in their flying career used an EFB, and 219 out of 236 participants (93\%) were currently using EFBs as of 2016. The sample size, variance in type of flying, and differences in type of operation provided an acceptable data spread to represent the industry. However, COTS type EFBs are still relatively new, so many companies are still making updates to EFB policies and procedures. More than half of the participants (149 of 236) indicated that their operator was planning to change either the software or hardware or switch from paper charts.

The pilots that participated in the survey were asked if new pilots should use COTS EFBs during their initial flight training. This question was answered regardless as to whether that pilot was currently using EFBs at their respective operator. Most participants (74\%) either agreed or strongly agreed that pilots should use EFBs for initial flight training. There were very few participants that strongly disagreed (6\%), indicating that they believe paper charts should be mastered first. This introduces a challenge for professional pilot flight programs, as they must consider when a pilot in training begins using EFBs.

A timeline of COTS EFB usage was discovered as well. Nearly half of the participants (117of 236) indicated that their current operator was using EFBs prior to January 2015. This data indicated a large increase in the use of EFBs in the past several years, from 22\% of participants in January 2013 to $87 \%$ of participants in January 2016.

As for the devices, the Apple iPad was reported as the most common device (174 of 206 EFB users), with the Microsoft Surface reported as the second most common (23 of $206 \mathrm{EFB}$ users). Only nine participants (4\%) were using a different type of COTS EFB device. This may speak to the influence that a major airline might have on a regional carrier. For example, if an air carrier elected to go with a 
particular device and software, then their respective regional feeders may have elected the same options.

As the iPad is the most common device, Jeppesen is the most common software. Jeppesen software was used by $84 \%$ of the participants using EFBs. ForeFlight Mobile was the second highest reported software $(11 \%)$. This was expected, as Jeppesen has been a leader in the aviation chart business for decades. ForeFlight Mobile is a dominant flight planning software in general aviation. However, as this data indicates, professionals continue to use Jeppesen charts, which is coded with Jeppesen symbols.

Several responses (19) indicated that dispatch battery charge was predicated upon the length of the duty day, planned flight hours or number of legs. Operators must consider unforeseen delays as a factor, as in many cases duty time is longer than planned due to weather, traffic, and other unpredictable circumstances. Several responses indicated a required start day charge, and then $10 \%$ more based upon planned flight hours or number of legs. Unfortunately, a few participants (3) directly admitted an ignorance of these requirements, but admitted there was indeed a requirement. This could be an indirect indicator as to the quality of training at their respective operators. Once an operator receives approval for EFB use, it is the responsibility of the operator to train their pilots on EFB battery charge requirements. However, the majority of participants worked for air carriers, which indicates that they had received training on their specific device and software. Most participants were familiar with these requirements.

Dispatch battery charge requirements were extremely varied. A large portion (44) of the applicable 206 participants currently using EFBs did not indicate a required charge for dispatch. This could be a result of Part 91 pilots, who do not need operational approval to use COTS EFBs (excluding Part 91F and Part 91K). There were 33 participants that flew Part 91 and used EFBs. Twenty-five of those 33 could charge the device in flight. Twelve of those pilots that could charge their device in flight indicated there was no minimum EFB charge for dispatch. This indicates that nearly half of Part 91 operators required a minimum EFB charge for dispatch despite the ability to charge the tablet in flight.

If there was a minimum EFB charge for dispatch, the requirement was most commonly based upon battery charge at the start of the day, with $80 \%$ as an average. Some participants indicated lower charge requirements, which could have been linked to the ability to charge the EFB during flight. Only four participants indicated a required dispatch charge of less than $50 \%$, and each of those participants 
indicated they could charge the device in flight. Four participants also indicated that one of the two EFBs on board could be dispatched as low as $20 \%$, as long as the combined charge between the two devices was at least $80 \%$.

Despite the overall performance and reliability of the devices, several operators continued to require paper backup navigation charts in the airplane. Of the 206 participants currently using EFBS, 30\% carried paper backup charts and maintained paper backup chart currency. With the American Airlines software debacle in mind, there are still operators requiring backup charts in case a software update or other issue causes unusable EFBs for their respective pilots. At the time of the survey, Southwest employed more than 9,000 pilots, and American Airlines employed more than 8,000. At each company, the device and software are standardized so that a system-wide software problem could lead to delays or cancellations of dozens of flights.

The functionality of COTS EFBs continues to expand with additional operational approvals. In addition to the anticipated functions, participants reported that they are now using EFBs for recurrent training, checklists, deicing information such as holdover times, and EFB software manuals. It is then logical to assume that this trend will continue and that more EFB functions will be added and approved in the future.

Approximately one in three participants (34\%) reported some problem with their EFB during preflight or in-flight. Most participants that were using EFBs at the time of the survey were using them for at least one year. The two most common software providers for COTS EFBs were Jeppesen and ForeFlight Mobile. Figure 10 indicated that these two applications had very similar trouble rates for pilots and that as a pilot uses the software more, the chance of encountering trouble increases. This analysis was completed with no correlation to the type of hardware (tablet) used.

Since Jeppesen was such a common application used by the participants, the hardware (tablets) were analyzed for reliability when associated with Jeppesen software. The clear majority of participants using EFBs (156 of 236) used Jeppesen software on either an Apple iPad or Microsoft Surface tablet. The iPad's reliability was considerably better, with a $27 \%$ reporting trouble accessing information as opposed $68 \%$ on the Surface throughout three years of operation. None of the participants that indicated trouble using Jeppesen Software on a Microsoft Surface tablet were using that combination for more than three years. It is important to note that the Surface tablet is somewhat newer than the iPad, first released in 2012 as 
opposed to 2010. Thus, Jeppesen's software division may have unique relationships with Apple and Microsoft hardware developers. The reliability analysis of Jeppesen software on Apple iPad and Microsoft Surface products indicated that the software is significantly more reliable on the Apple iPad.

\section{Limitations}

Despite gathering acceptable data from several operators, this research did have limitations. The research was focused on portable COTS type EFBs, which excludes several other types of EFBs in use. Class 3 EFBs are permanently mounted on the aircraft and have additional connectivity with aircraft systems. Some participants indicated that they used a COTS Class 1 or 2 EFB as well as a Class 3 EFB during flight operations.

The sample size was acceptable, but there were limitations associated with the participants. It is entirely possible that several participants were flying for the same operators, leading to similar answers on multiple questions. There were 236 participants representing 80 different operators. There were five operators that had 10 or more participants, with the most represented operator having 32 participants. This information could have influenced the results, as those 32 participants should have answered several questions similarly based upon company EFB policies and procedures.

When completing the survey, there was one participant which used two types of software but then reported a complication without noting which software was involved. There were four others that used two types of software, but did not report complications, and one which specified a complication with one software. This was a survey design flaw, as the primary investigator did not expect participants to be using two types of chart software.

This study was also limited because the software used by each participant may have been unique for their operator. For example, a pilot at one airline may have specifically tailored Jeppesen downloads that are different than the software used at another airline. This study did not scrutinize EFB reliability among different operators. A similar limitation applied to the COTS tablets, as any and all versions of one type of tablet were included in one set of data. For example, an iPad 1 and an iPad Air were all considered "iPad."

One limitation to the Jeppesen reliability analysis for the Apple iPad and Microsoft Surface tablets related to the total number of applicable participants. There were 133 participants using the Jeppesen/iPad combination and only 22 
participants using the Jeppesen/Surface combination. Though these groups are dissimilar in total numbers, the results indicated a significant advantage in reliability for the Jeppesen/iPad combination. The results indicate that a pilot has a higher chance of having trouble with the Jeppesen software on a Surface tablet within six months of use (36\%) than a pilot using the Jeppesen software on an iPad for more than three years $(27 \%)$.

This information may be linked to the total duration of use. Many participants using Jeppesen software on an iPad had been using this combination for at least one year (92\%). As for Jeppesen software users with Surface tablets, nearly half of these participants (45\%) had been using this combination for less than six months, and no applicable participants had been using this combination for more than three years. The Microsoft Surface tablet may have reliability issues with Jeppesen software simply because it is a newer device and operating system.

Another limitation was potential variations in pilot flight time for a given period. The survey gathered data based upon the number of months or years of use for EFBs. During these time periods, pilots may have variations in flight time and thus exposure to EFB problems. However, the vast majority of participants (161 of 236) were pilots flying Part 121, and these pilots typically fly a similar number of hours per a given month or year.

\section{Conclusion}

This study investigated how operators initially comply with FAA EFB guidance continue to abide throughout several years of use. The applicable COTS devices and software used have small variations. Associated EFB policies, such as charging capabilities, charging requirements, and EFB functions are also somewhat similar. The functionality of the devices continues to expand, especially when considering connectivity in the cockpit. This data, provided by the pilots that use COTS EFBs, is a concrete foundation upon which flight schools and professional pilot programs can model an EFB policy for their students. The most common COTS software (Jeppesen) had better reliability with Apple tablets over Microsoft tablets, and this information may be of use to operators and pilots. The findings are a static representation of COTS EFB usage, as the industry and associated policies are still in flux.

\section{Suggested Additional Research}

Additional research is suggested on several related topics. One such project could investigate the effects of age, culture, and environment on one's ability to 
effectively use an EFB (ageism and iPads). Data entry errors are becoming more problematic as some EFBs are used for takeoff performance calculations. The frequency and severity of such miscalculations should be investigated, as well as the crew verification process. Another important area to explore includes gathering data from flight schools about when their students begin using EFBs. The COTS EFB industry is now capable of multiple flight planning functions, perhaps making the E6B flight computer obsolete. Flight schools may also be able to contribute to this discussion. The functionality of EFBs continues to grow, but not all functions may be tied to one software or application. A study into the different applications that provide individual functions could further explore EFB modes of operation when a failure occurs. For example, if the Jeppesen chart software fails, that may or may not impact the pilot's ability to predict performance or retrieve weather information. 


\section{References}

Chandra, D. \& Kendra, A. (2010). Review of safety reports involving electronic flight bags. Proceedings from the International Symposium on Aviation Psychology. Retrieved from http://ntl.bts.gov/lib/44000/44100/44161/efb042010_1_.pdf

Chandra, D., Yeh, M. (2003). Design and evaluation of electronic flight bags (EFBs) version 2. Retrieved from http://ntl.bts.gov/lib/34000/34200/34292/DOT-VNTSC-FAA-03-07.pdf

Federal Aviation Administration. (2014). Advisory circular 120.76C: Guidelines for the certification, airworthiness, and operational use of electronic flight bags. Retrieved from http://www.faa.gov/documentlibrary/ media/advisory_circular/ac_120-76c.pdf

Hiltunen, D., Chase, S., Kendra, A., Jo, \& Young J. (2015). Electronic flight bag (EFB) 2015 industry survey. U.S. Department of Transportation. Retrieved from http://fsims.faa.gov/wdocs/other/final\%20report\%20\%20volpe\%202015\%20efb\%20industry\%20survey.pdf on 9/29/2016

Hughes, D. (2009). Airlines outline EFB benefits. Avionics Magazine, June.

Lau, S. (2016). An update on paperless cockpits. Professional Pilot Magazine. Retrieved from http://propilotmag.com/archives/2015/Nov\%2015/A4_Connectivity_p1.ht $\mathrm{ml}$

Mather, V. (2016, Oct 18). Bill Belichick throws in the tablet. The New York Times. Retrieved from http://www.nytimes.com/2016/10/19/sports/football/bill-belichickpatriots-might-be-a-mac-guy.html?_r=0

Myers, P. 2016. Commercial aircraft electronic checklists: Benefits and challenges. International Journal of Aviation, Aeronautics, and Aerospace. 3(1). doi: http://dx.doi.org/10.15394/ijaaa.1112

Sampigethaya, K., Poovendran, R., Shetty, S., Davis, T., \& Royalty C. (2011). Future e-enabled aircraft communications and security: The next 20 years and beyond. Proceedings of the Institute of Electrical and Electronics Engineers. 99(11). 
Thompson, P. (2015). Southwest shares lessons learned after one year with the EFB. Airways International Magazine. Retrieved from http://airwaysnews.com/blog/2015/07/16/southwest-efb/

United States Department of Transportation (2015). Certificated air carriers list. Retrieved from https://www.transportation.gov/policy/aviationpolicy/certificated-air-carriers-list

Van Wagenen, J. (2015). American Airlines, Jeppesen comment on EFB crash that grounded flights. Avionics Today. Retrieved from http://www.aviationtoday.com/av/topstories/American-Airlines-JeppesenComment-on-EFB-Crash-that-Grounded-Flights_84925.html 
Appendix A

Validation of Survey Questions Based Upon Advisory Circular 120.76C

The following is a list of direct references to AC $120.76 \mathrm{C}$ and the related survey questions used in this research.

1. "Do not use data-linked Meteorology Information (MET) and Aeronautical Information Service (AIS) products as the sole source for making tactical in-flight decisions regarding flight safety when avoiding adverse weather, airspace, or obstacle hazards" (p.8).

Associated Survey question(s):

Indicate the information and flight planning data that your current EFB provides as acceptable data for your company and FAA requirements.

Have you ever had trouble accessing information on your EFB during preflight or in flight? If you answer yes, please explain.

2. "Type B W\&B applications use data management software to provide data reference and mathematical calculations to simplify determination of aircraft W\&B” (p. 8).

Associated Survey Question(s):

Indicate the information and flight planning data that your current EFB provides as acceptable data for your company and FAA requirements.

3. "Operational procedures must be established to verify the accuracy of inputs and outputs of Type B application software. Validation is a necessary part of risk mitigation to ensure the effective function and reliability of EFB hardware, software, and procedures" (p. 9).

Associated Survey Question(s):

Have you ever had trouble accessing information on your EFB during preflight or in flight? If you answer yes, please explain. 
How long has your company been using EFBs?

Does your company currently use EFBs in any manner (including trial period)?

What type of device does your company currently use?

What chart software or app does your company currently use?

4. "Two or more operational EFBs are required to remove paper products that contain Type B software applications for in-flight use" (p. 10).

Associated Survey Question(s): your $\operatorname{EFB}(\mathrm{s})$ ?

Does your company require current paper charts as a backup to

5. "Operators transitioning to a paperless or reduced-paper cockpit should carry paper backups of all the information on the EFB during a validation period" (p. 23)

Associated Survey Question(s):

How long has your company been using EFBs?

Does your company require current paper charts as a backup to your $\mathrm{EFB}(\mathrm{s})$ ?

6. "Battery-powered EFBs that have aircraft power available for recharging the EFB battery are considered to have a suitable backup power source" (p. 10).

Associated Survey Question(s):

Are you able to charge your device in flight on any aircraft you are currently assigned to? This may or may not include all aircraft or tail numbers of one type.

7. "A battery or batteries with a combined useful battery life to ensure EFB is operational during taxi and flight operations to include diversions and expected delays" (p. 11). 


\section{Associated Survey Question(s):}

Is there a minimum battery charge required for departure on the pilot(s) $E F B(s)$ according to your operations specifications and/or EFB authorization?

If you answered "yes" to question 11, please indicate the amount of charge required for dispatch and any other related requirements. If not applicable, leave the response blank.

8. "Text displayed on the EFB should be legible to the typical user at the intended viewing distance(s) and under the full range of lighting conditions expected on a flight deck, including use in direct sunlight" ( $p$. 16).

Have you ever had trouble accessing information on your EFB during preflight or in flight? If you answer yes, please explain. 